\title{
Reduction of RKIP expression promotes nasopharyngeal carcinoma invasion and metastasis by activating Stat3 signaling
}

\author{
Qiu-Yan He ${ }^{1,2}$, Hong-Mei Yi ${ }^{1,2}$, Hong $\mathbf{Y i}^{1,2}$, Ta Xiao ${ }^{1,2}$, Jia-Quan $Q u^{1,2}$, Li Yuan ${ }^{1,2}$, Jin- \\ Feng Zhu ${ }^{1,2}$, Jiao-Yang Li, ${ }^{1,2}$, Yuan-Yuan Wang ${ }^{1,2}$, Li-Na $\mathrm{Li}^{1,2}$, Juan Feng ${ }^{1,2}$, Shan- \\ Shan Lu ${ }^{1,2}$ and Zhi-Qiang Xiao ${ }^{1,2}$ \\ ${ }^{1}$ Research Center of Carcinogenesis and Targeted Therapy, Xiangya Hospital, Central South University, Changsha, Hunan, \\ China \\ 2 The Higher Educational Key Laboratory for Cancer Proteomics and Translational Medicine of Hunan Province, Xiangya \\ Hospital, Central South University, Changsha, Hunan, China
}

Correspondence to: Zhi-Qiang Xiao, email: zqxiao2001@hotmail.com

Keywords: nasopharyngeal carcinoma; metastasis; RKIP; Stat3; metastatic suppressor

Received: February 21, $2015 \quad$ Accepted: March 20,2015 Published: April 15, 2015

This is an open-access article distributed under the terms of the Creative Commons Attribution License, which permits unrestricted use, distribution, and reproduction in any medium, provided the original author and source are credited.

\section{ABSTRACT}

The role and underlying mechanism of Raf kinase inhibitory protein (RKIP) in nasopharyngeal carcinoma (NPC) metastasis remain unclear. Here, we showed that RKIP was downregulated in the NPC with high metastatic potentials, and its decrement correlated with NPC metastasis and poor patient survival, and was an independent predictor for reduced overall survival. With a combination of loss-offunction and gain-of-function approaches, we observed that high expression of RKIP reduced invasion, metastasis and epithelial to mesenchymal transition (EMT) marker alternations of NPC cells. We further showed that RKIP overexpression attenuated while RKIP knockdown enhanced Stat3 phosphorylation and activation in NPC cells; RKIP reduced Stat3 phosphorylation through interacting with Stat3; Stattic attenuated NPC cell migration, invasion and EMT marker alternations induced by RKIP knockdown, whereas Stat3 overexpression restored NPC cell migration, invasion and EMT marker alternations reduced by RKIP overexpression. In addition, there was an inverse correlation between RKIP and phospho-Stat3 expression in the NPC tissues and xenograft metastases. Our data demonstrate that RKIP is a metastatic suppressor and predictor for metastasis and prognosis in NPC, and RKIP downregulation promotes NPC invasion, metastasis and EMT by activating Stat3 signaling, suggesting that RKIP/ Stat3 signaling could be used as a therapeutic target for NPC metastasis.

\section{INTRODUCTION}

Nasopharyngeal carcinoma (NPC) is one of the most common malignant tumors in southern China and Southeast Asia [1]. Early metastasis is one of distinctive characteristics of NPC [2]. Although NPC is sensitive to radiotherapy, significant rates of relapse and distant metastasis still occur after therapy, which has been recognized as a major cause for NPC lethality [3]. However, the molecular mechanism of NPC metastasis is not yet well-defined. To develop better diagnosis and treatment approaches, it is important to understand the molecular basis of NPC metastasis.

Raf kinase inhibitory protein (RKIP) was initially identified as phosphatidylethanolamine-binding protein in bovine brain [4]. It was later identified RKIP as a physiological inhibitor of Raf kinase, antagonizing Raf1/MEK/ERK pathway [5]. Further exploration revealed that RKIP inhibits NF- $\mathrm{KB}[6]$ and GRK2 (G proteincoupled receptor kinase 2) signaling [7], and activates GSK-3 $\beta$ signaling [8]. The recent study has found that RKIP blocks Stat3 signaling pathway [9]. Accumulative studies have showed that loss or downregulation of RKIP enhances epithelial to mesenchymal transition (EMT), motility, invasion and metastasis of tumor cells through regulating these pivotal intracellular signaling cascades $[10,11]$. Previous studies have demonstrated that RKIP inhibits metastasis in prostate [12-14], breast [15], ovarian 
[16], colorectal [17, 18], and gastric cancer [19], and melanoma [20], and its expression is predictive of clinical outcome: better outcome with higher expression [12-19]. Additionally, downregulation of RKIP has been shown to impact therapy through conferring tumor radioresistance [21] and chemoresistance [22]. Thus, RKIP is considered to be a metastasis suppressor protein $[10,11]$.

Stat3, known to be activated by cytokines, growth factors, and oncogenic proteins, is constitutively activated in a number of malignancies including NPC [23], and promotes cell survival, EMT, invasion and metastasis [2426]. Stat3, a latent cytoplasmic transcription factor, upon phosphorylated activation, translocates to the nucleus and binds to specific regulatory elements that control gene expression [27]. It has been reported that Stat 3 constitutive activation and nuclear localization are associated with NPC cell growth, cancer stem-like characteristics and metastasis [23, 28-30], and activated Stat3 is a target for anti-NPC drug discovery [29-31].

In our previous comparative proteomic study, RKIP was identified as a downregulated protein in NPC tissues compared to normal nasopharyngeal mucosal tissues [32]. In another study, we also found that RKIP downregulation is associated with NPC radioresistance, and it is a potential biomarker for predicting NPC radiosensitivity [33]. LI et al. reported that RKIP expression is negatively associated with the distant metastasis of NPC, and has a predictive value for its distant metastasis [34]. However, the role and mechanism of RKIP downregulation in NPC metastasis are still unclear, and need to be elucidated.

As mentioned above, activated-Stat 3 is correlated with NPC invasion and metastasis [23, 28-30], and RKIP blocks Stat3 activation in prostate cancer cells [9]. Furthermore, there is an inverse association between RKIP and Stat 3 expression in gastric cancer tissues, and the high expression of cytoplasmic RKIP and nuclear Stat3 is correlated with poor patient prognosis [35]. Therefore, RKIP downregulation promotes tumor invasion and metastasis possibly through activating Stat 3 signaling, but it needs to be validated.

In this study, we examined RKIP expression in thirty normal nasopharyngeal mucosal tissues, one hundred and twenty-seven NPC tissues with different metastatic potential and twenty paired neck lymph node metastases, analyzed the association of RKIP expression with NPC metastasis and patient prognosis; determined the role of RKIP in NPC invasion and metastasis both in vitro and in vivo; and explored whether Stat 3 signaling mediates the effects of RKIP on NPC invasion and metastasis.

\section{RESULTS}

\section{Expression levels of RKIP are associated with the metastasis and prognosis of NPC}

Although RKIP expression has been shown to be associated with the metastasis and patient outcome of human cancers, its information in NPC is scarce. Accordingly, we were interested in assessing the expression and clinical significance of RKIP in NPC biopsies. IHC was performed in a cohort of NPC tissues including 79 NPCs with metastasis (neck lymphonode and/or distant metastasis) and 48 NPCs without metastasis, as well as 20 paired neck lymphonode metastases (LNMs) and 30 normal nasopharyngeal mucosa (NNM). The clinicopathologic features of the patients used in the present study are shown in Table 1 . We observed that RKIP expression was dramatically reduced in the NPCs relative to NNM, in the NPCs with metastasis relative to NPCs without metastasis, and was not detectable in the almost all LNMs (Figure 1A, Table 2). The relationship between clinicopathological variables and RKIP expression is shown in Table 3. As shown in this table, reduced RKIP expression was correlated with advanced clinical stage and high frequent lymphonode and distant metastasis. Kaplan-Meier analysis revealed that low RKIP level in NPC tissues significantly correlated with the markedly reduced patient overall survival (Figure 1B). A univariate Cox regression analysis showed that RKIP expression level, lymphonode and distant metastasis and TNM stage markedly affected the overall survival of NPC patients (Table 4). A multivariate Cox regression analysis confirmed that low RKIP expression was an independent predictor for reduced patient overall survival (Table 4). These results indicate the importance of RKIP expression level in the NPC metastasis and patient prognosis.

\section{RKIP downregulation promotes NPC cell migration and invasion in vitro}

To investigate the effect of RKIP in NPC cell migration and invasion in vitro, we established 5-8 NPC cell lines with stable overexpression of RKIP, 6-10B NPC cell lines with stable knockdown of RKIP, and their corresponding control cell lines (Figure 2A). As shown in Figure 2B, RKIP overexpression decreased while RKIP knockdown increased NPC cell migration and invasion as determined by Scratch wound-healing and Matrigel invasion assays. These results demonstrated that RKIP downregulation promoted NPC cell migration and invasion in vitro. 
Table 1: The clinicopathological parameters of 127 patients with nasopharygeal carcinoma

\begin{tabular}{lcc}
\hline Variable & No. of patients & \% \\
\hline Gender & 92 & 72.44 \\
$\quad$ Male & 35 & 27.56 \\
$\quad$ Female & 57 & 44.88 \\
Age(y) & 24 & 55.12 \\
$\quad \geq 48$ & & \\
$\quad<48$ & 43 & 34.65 \\
Primary tumor(T) stage & 84 & 65.35 \\
T1-2 & & \\
T3-4 & 49 & 38.58 \\
Lymph node(N) metastasis & 28 & 61.41 \\
N0 & & \\
N1-3 & 99 & 77.95 \\
Distant metastasis(M) & 28 & 22.05 \\
M0 & & \\
M1 & 24 & 18.9 \\
Clinical TNM stage & 103 & 81.1 \\
I-II & & \\
III-IV & &
\end{tabular}
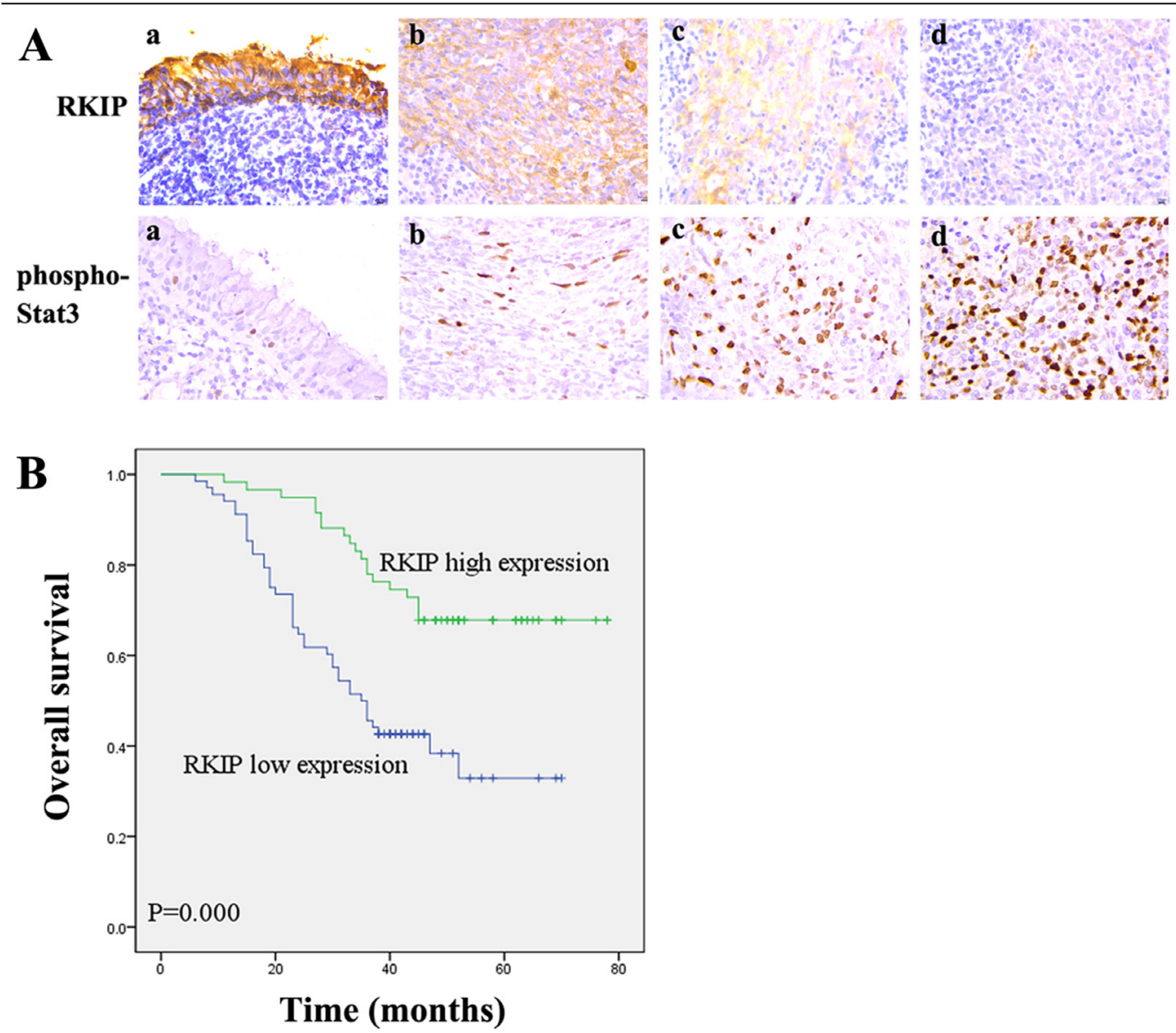

Figure 1: Association of RKIP expression levels with NPC metastasis and overall survival of the patients. A. a representative result of RKIP and phospho-Stat3 immunohistochemical staining in normal nasopharyngeal mucosa (a), NPC without metastasis (b), NPC with metastasis (c), and lymphonode metastasis (d). Original magnification, $\times 200$. B. Kaplan-Meier survival analysis for NPC patients according to the expression levels of RKIP. NPC patients with low RKIP expression have a significantly worse overall survival than those with high RKIP expression. The log-rank test was used to calculate $\mathrm{p}$ value. 
Table 2: Expression of RKIP and phospho-Stat3 in 127 nasopharygeal carcinomas

\begin{tabular}{lcccc}
\hline & NNM & NPC without metastasis & NPC with metastasis & LNM \\
\hline RKIP & & 31 & 29 & 2 \\
High(4-6) & 25 & 17 & 50 & 18 \\
Low(0-3) & 5 & & & \\
Phospho-Stat3 & & 18 & 48 & 19 \\
High(4-6) & 7 & 30 & 31 & 1 \\
Low(0-3) & 23 & & \\
\hline
\end{tabular}

NNM, normal nasopharyngeal mucosa; LNM, lymphonode metastases.

$p<0.01$ or 0.05 by $\chi^{2}$ test, NNM $v s$. NPC; NPC without metastasis $v s$. NPC with metastasis; NPC with metastasis $v s$. LNM

Table 3: Association between RKIP expression and clinicopathological characteristics in 127 nasopharyngeal carcinomas.

\begin{tabular}{|c|c|c|c|c|}
\hline \multirow[b]{2}{*}{ Variable } & \multirow[b]{2}{*}{$\mathbf{n}$} & \multicolumn{2}{|c|}{ Expression level } & \multirow[b]{2}{*}{$P$} \\
\hline & & $\operatorname{Low}(0-3)$ & $\operatorname{High}(4-6)$ & \\
\hline \multicolumn{5}{|l|}{ Gender } \\
\hline Male & 92 & 47 & 45 & 0.368 \\
\hline Female & 35 & 21 & 14 & \\
\hline \multicolumn{5}{|l|}{$\operatorname{Age}(y)$} \\
\hline$<48$ & 57 & 32 & 25 & 0.596 \\
\hline$\geq 48$ & 70 & 36 & 35 & \\
\hline \multicolumn{5}{|c|}{ Primary tumor(T) stage } \\
\hline $\mathrm{T} 1-2$ & 43 & 25 & 18 & 0.881 \\
\hline T3-4 & 84 & 50 & 34 & \\
\hline \multicolumn{5}{|c|}{ lymph node(N) metastasis } \\
\hline No & 49 & 18 & 31 & $0.003^{\#}$ \\
\hline N1-3 & 78 & 50 & 28 & \\
\hline \multicolumn{5}{|c|}{ Distant metastasis(M) } \\
\hline M0 & 99 & 48 & 51 & $0.032^{*}$ \\
\hline M1 & 28 & 20 & 8 & \\
\hline \multicolumn{5}{|c|}{ Clinical TNM stage } \\
\hline I-II & 24 & 8 & 16 & $0.028^{*}$ \\
\hline III-IV & 103 & 60 & 43 & \\
\hline
\end{tabular}




\section{RKIP downregulation promotes NPC cell metastasis in vivo}

To explore the role of RKIP in NPC metastasis in vivo, we tested the effect of RKIP in a xenograft metastasis model in which RKIP knockdown 6-10B cells, RKIP overexpression 5-8F cells, and their corresponding control cells were used to generate pulmonary metastases in nude mice. As shown in Figure $2 \mathrm{C}$, pulmonary metastases generated by RKIP overexpression 5-8F cells were significantly less than those generated by empty vector-transfected $5-8 \mathrm{~F}$ cells. Moreover, although control 6-10B cells without metastatic potential did not generate pulmonary metastases, RKIP knockdown 6-10B cells could generate pulmonary metastases (Figure 2C). The results suggested that RKIP played a crucial role in inhibiting NPC metastasis, and its downregulation promoted NPC cell metastasis in vivo.

A
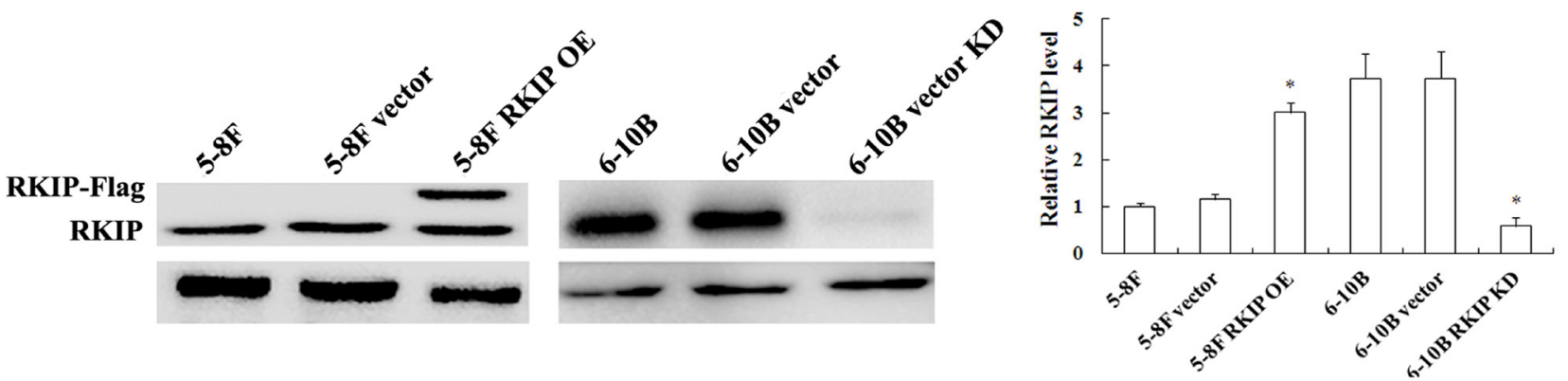

B
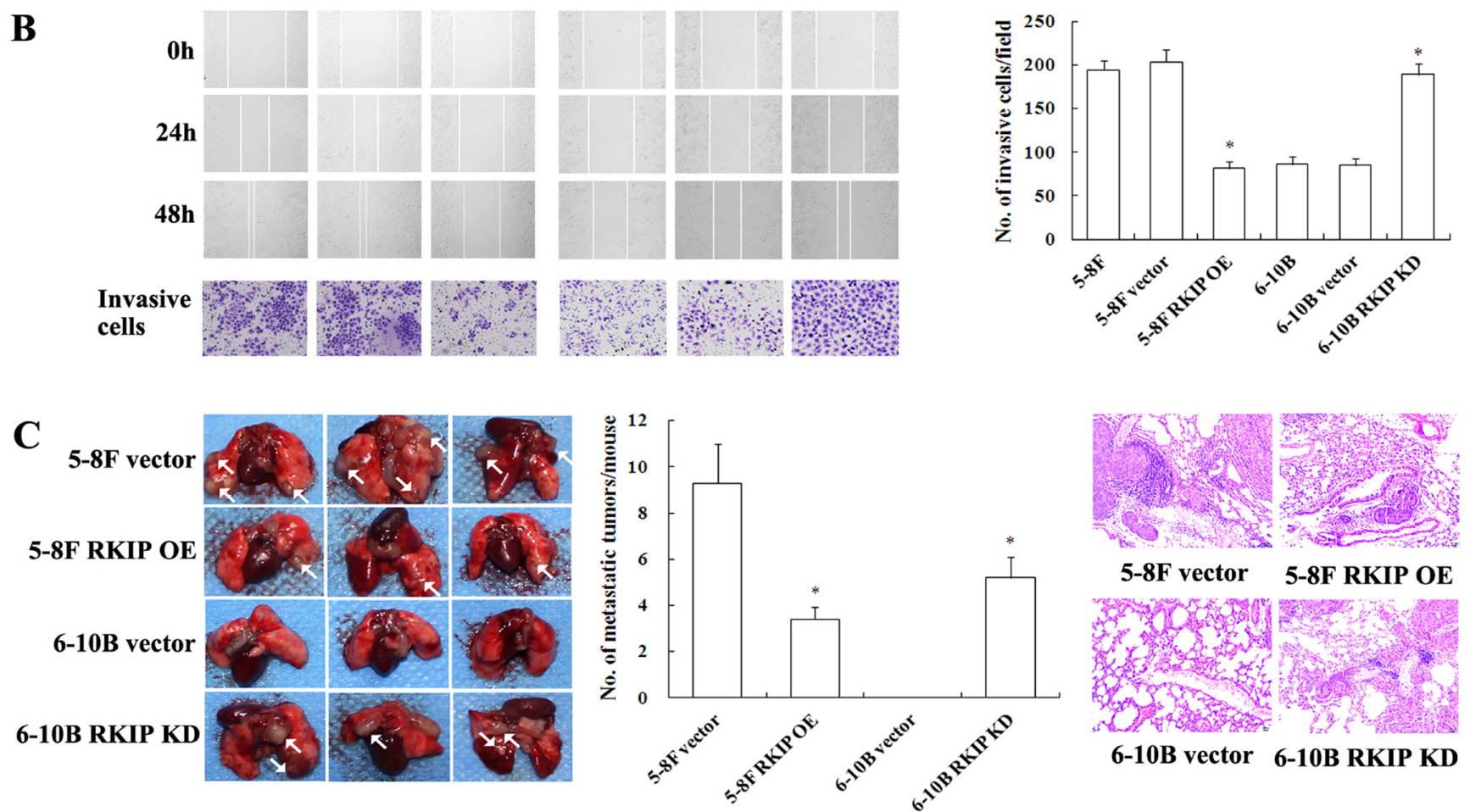

Figure 2: The effects of RKIP expression changes on in vitro NPC cells migration and invasion and in vivo metastasis. A. (left) a representative result of Western blotting shows the levels of RKIP expression in 5-8F and 6-10B NPC cells and their transfectants; (right) histogram of relative RKIP expression levels in 5-8F and 6-10B NPC cells and their transfectants as determined by densitometric analysis. B. (left top) a representative result of scratch wound-healing assay shows migration of 6-10B and $5-8 \mathrm{~F}$ cells and their transfectants. Images were taken at 0,24 and $48 \mathrm{~h}$ after wounding under the inverted microscope; (left bottom) a representative result of Matrigel invasion assay shows invasion of $6-10 \mathrm{~B}$ and $5-8 \mathrm{~F}$ cells and their transfectants. Invasive cancer cells were photographed at $48 \mathrm{~h}$ after incubation; (right) histogram of average numbers of invasive cancer cells per microscopic field. C. in vivo metastasis assays of NPC cells with RKIP expression changes. (left) RKIP overexpression 5-8F cells, RKIP knockdown 6-10B cells, and their corresponding empty vector-transfected cells were injected into the tail vein of nude mice, and the representative photography of lung is shown; (middle) histogram of average numbers of lung metastases per mouse; (right) the representative H\&E staining of lung tissues shows metastatic tumors. Metastases generated by RKIP overexpression $5-8 \mathrm{~F}$ cells are significantly less than those generated by empty vector-transfected $5-8 \mathrm{~F}$ cells. The empty vector-transfected 6-10B cells do not generate metastases, but RKIP knockdown 6-10B cells can generate metastases. Columns, mean values; bars, S.D. *, $p<0.01$. Vector, transfcted with an empty vector; OE, overexpression; KD, knockdown. 


\section{RKIP downregulation induces EMT-like molecular alternations in NPC cells}

EMT is a key event in cancer invasion and metastasis [36]. Previous studies have indicated that RKIP overexpression inhibits EMT in prostate cancer cells $[37,38]$. Therefore, we analyzed the effect of
RKIP on the expression of representative EMT markers in NPC cells. QRT-PCR and Western blotting analyses showed that mesenchymal markers Vimentin and $\mathrm{N}$-cadherin significantly upregulated while epithelial marker E-cadherin significantly downregulated in RKIP knockdown 6-10B cells compared with control 6-10B cells (Figure 3A and 3B). Conversely, Vimentin and N-cadherin significantly downregualted while E-cadherin significantly

A


Figure 3: The regulation of RKIP on the expression of EMT-like cellular markers in NPC cells and their xenograft metastases. A. mRNA expression levels of E-cadherin, N-cadherin and Vimentin in 5-8F and 6-10B NPC cells and their transfectants detected by qRT-PCR. Columns, mean values from triplicate experiments; bars, S.D. ${ }^{*}, p<0.01$. B. a representative result of Western blotting shows the levels of E-cadherin, N-cadherin and Vimentin in 5-8F and 6-10B NPC cells and their transfectants. C. a representative result of immunofluorescent staining shows the levels of E-cadherin, N-cadherin and Vimentin in RKIP overexpression 5-8F cells, RKIP knockdown 6-10B cells and their corresponding empty vector-transfected cells. D. (left) a representative result of immunohistochemical staining of RKIP, E-cadherin, N-cadherin, Vimentin and phospho-Stat3 in the lung metastases of RKIP overexpression 5-8F cells, RKIP knockdown 6-10B cells and empty vector-transfected $5-8 \mathrm{~F}$ cells; (right) histogram of expression levels of RKIP, E-cadherin, N-cadherin, Vimentin and phospho-Stat3 in the lung metastases. Original magnification, $\times 200$. Columns, mean values from 10 mice; bars, S.D. *, $p<$ 0.01. E-cad, E-cadherin; N-cad, N-cadherin; Vim, Vimentin. Vector, transfcted with an empty vector; OE, overexpression; KD, knockdown. 
Table 4: Univariate and multivariate analyses of selected prognostic factors for overall survival using Cox regression model ( $\mathrm{N}=127)$.

\begin{tabular}{|c|c|c|c|c|}
\hline \multirow{3}{*}{ Variable } & \multicolumn{4}{|c|}{ Overall survival } \\
\hline & \multicolumn{2}{|c|}{ Univariate analysis } & \multicolumn{2}{|c|}{ Multivariate analysis } \\
\hline & $\boldsymbol{P}$ & HR $(95 \%$ CI) & $\boldsymbol{P}$ & HR( $95 \%$ CI $)$ \\
\hline \multicolumn{5}{|l|}{ Gender } \\
\hline Male vs. Female & 0.295 & $1.377(0.757-2.506)$ & 0.547 & $0.815(0.420-1.584)$ \\
\hline \multicolumn{5}{|l|}{ Age(ys) } \\
\hline$<48 v s . \geqslant 48$ & 0.056 & $1.679(0.988-2.856)$ & 0.312 & $1.349(0.755-2.412)$ \\
\hline \multicolumn{5}{|c|}{ Primary tumor(T) stage } \\
\hline T1-2 vs.T3-4 & 0.086 & $1.659(0.931-2.957)$ & 0.148 & $1.630(0.337-1.179)$ \\
\hline $\begin{array}{l}\text { lymph node(N) me } \\
\text { N0 vs. N1-3 }\end{array}$ & $0.001^{\#}$ & $2.569(1.485-4.799)$ & 0.493 & $0.779(0.381-1.592)$ \\
\hline \multicolumn{5}{|l|}{ Distant etastasis(M) } \\
\hline M0 vs. M1 & $0.000^{\#}$ & $7.864(4.539-13.625)$ & $0.000^{\#}$ & $6.711(3.761-11.974)$ \\
\hline \multicolumn{5}{|l|}{ Clinical TNM stage } \\
\hline I-II $v s$. III-IV & $0.001^{\#}$ & $10.950(2.657-45.130)$ & $0.009^{\#}$ & $6.985(1.639-29.763)$ \\
\hline \multicolumn{5}{|c|}{ RKIP expression level } \\
\hline Low $v s$. high & $0.000^{\#}$ & $0.348(0.200-0.605)$ & $0.000^{\#}$ & $0.335(0.189-0.596)$ \\
\hline
\end{tabular}

upregulated in RKIP overexpression 5-8F cells compared with control 5-8F cells (Figure 3A and 3B). Moreover, immunofluorescent staining also revealed that the similar expression pattern of Vimentin, N-cadherin and E-cadherin in RKIP knockdown 6-10B cells and RKIP overexpression $5-8 \mathrm{~F}$ cells (Figure 3C). The results suggested that RKIP downregulation induced EMT in NPC cells.

Next, we detected the expressions of representative EMT markers in the xenograft metastases using IHC. The results showed that Vimentin and $\mathrm{N}$-cadherin significantly downregulated while E-cadherin was significantly upregulated in the metastases of RKIP overexpressing$5-8 \mathrm{~F}$ cells as compared to control $5-8 \mathrm{~F}$ cells metastases (Figure 3D). Moreover, the expression levels of Vimentin, $\mathrm{N}$-cadherin and E-cadherin in the metastases of RKIP knockdown 6-10B cells, parental cells of which lack metastatic potential, were comparable to those in the metastases of control $5-8 \mathrm{~F}$ cells with high metastatic potential. These results support our in vitro findings. Taken together, the results implied that RKIP downregulation enhanced NPC cell invasion and metastasis possibly by inducing EMT.

\section{RKIP downregulation activates Stat3 signaling in NPC cells}

To determine the signaling mechanisms of RKIPregulating NPC cell invasion and metastasis, we detected the effects of RKIP on the phosphorylated level of ERK-
$1 / 2$, Stat 3, NF- $\kappa$ B and GSK-3 $\beta$ by Western blotting. The results showed that the phosphorylated level of Stat3 (Tyr705), ERK-1/2 (Thr202/Tyr204), IKK- $\alpha$ (Ser176)/ $\beta(\operatorname{Ser} 177)$ and IкB- $\alpha$ (Ser32) obviously increased, and that of GSK-3 $\beta$ (Ser9) obviously decreased in RKIP knockdown 6-10B cells compared with control 6-10B cells. Conversely, the phosphorylated level of Stat3 (Tyr705), ERK-1/2 (Thr202/Tyr204), IKK- $\alpha($ Ser176)/ $\beta$ (Ser177) and IкB- $\alpha$ (Ser32) obviously decreased, and that of GSK-3 $\beta$ (Ser9) oviously increased in RKIP overexpression $5-8 \mathrm{~F}$ cells compared with control $5-8 \mathrm{~F}$ cells (Figure 4A). The results indicated that RKIP inhibited ERK, NF- $\kappa$ B, and Stat3, and activated GSK-3 $\beta$ in NPC cells, which is consistent with previous reports [5, $6,8,9]$. Although RKIP can block Stat3 activity [9], it is unknown whether Stat3 mediates RKIP-regulating tumor cell invasion and metastasis. Therefore, we selected RKIP/ Stat3 signaling for further study.

Once phosphorylated and activated, Stat3 enters the nucleus and regulates gene transcription [27]. Accordingly, we detected nuclear phospho-Stat3 expression in the NPC cells with RKIP overexpression or knockdown by immunefluorescent staining. We found that the number of cells expressing nuclear phospho-Stat3 is markedly increased in RKIP knockdown 6-10B cells, whereas obviously decreased in RKIP overexpression $5-8 \mathrm{~F}$ cells compared with their corresponding control cells (Figure 4B), indicating that RKIP inhibited Stat3 nuclear translocation in NPC cells. We next detected the ability of RKIP to inhibit transcriptional activity of Stat3 
$\mathbf{A}$



IкB- $\alpha \longrightarrow$

$\beta$-actin

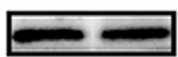

B
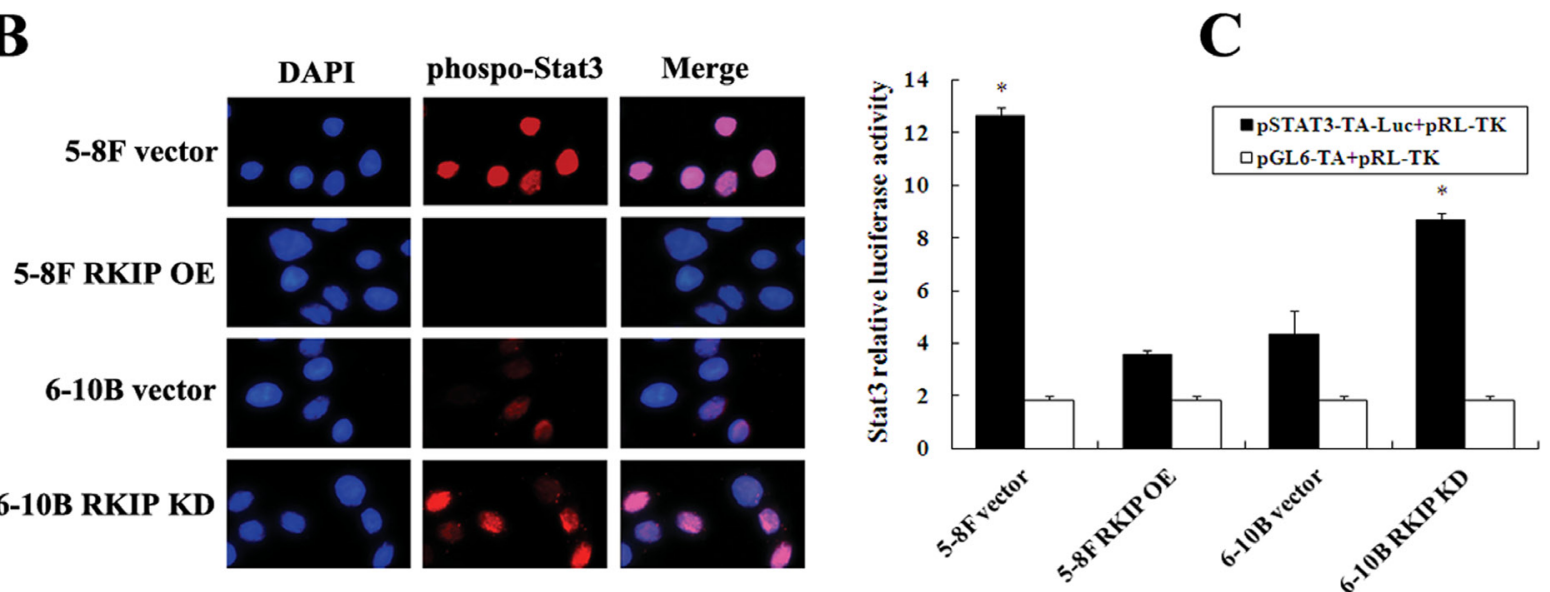

$\mathbf{D}$


Figure 4: The regulation of RKIP on the activity of NPC cellular signaling pathways. A. a representative result of Western blotting shows the phosphorylated and total levels of Stat3, ERK-1/2, IKK- $\alpha / \beta$, IкB- $\alpha$, and GSK-3 $\beta$ in RKIP overexpression $5-8 \mathrm{~F}$ cells, RKIP knockdown 6-10B cells and their corresponding empty vector-transfected cells. B. a representative result of immunofluorescent staining shows the nuclear translocation of phospho-Stat3 in RKIP overexpression 5-8F cells, RKIP knockdown 6-10B cells and their corresponding empty vector-transfected cells. C. Stat3 luciferase reporter activity in RKIP overexpression 5-8F cells, RKIP knockdown $6-10 \mathrm{~B}$ cells and their corresponding empty vector-transfected cells. Columns, mean values from triplicate experiments; bars, S.D. *, $p$ $<0.01$. D. a representative result of Co-IP shows RKIP interacting with and inhibiting Stat3 phosphorylation in RKIP overexpression $5-8 \mathrm{~F}$ cells. Cells were lysed in RIPA buffer, a portion of the sample was removed as the IP input and the remaining supernatant was immunoprecipitated with RKIP antibody and protein A agarose. Immunocomplexes were separated by SDS-PAGE, transferred onto PVDF membrane, and detected with Stat3, phospho-stat 3 or RKIP antibody. The input samples were examined for the expression of the indicated proteins. Vector, transfcted with an empty vector; OE, overexpression; KD, knockdown. 
using a luciferase reporter assay. The results showed that Stat3 luciferase reporter activity was remarkably increased in RKIP knockdown 6-10B cells, whereas remarkably decreased in RKIP overexpression 5-8F cells compared with their corresponding control cells (Figure 4C), demonstrating that RKIP was able to inhibit Stat3 transcriptional activity. Taken together, the results demonstrated that RKIP blocked Stat3 signaling in NPC cells.

It has been reported that RKIP overexpression resulted in constitutive physical interaction with Stat 3 and blocked c-Src-phosphorylating and activating Stat3 [9]. Therefore, we detected whether RKIP interacts with, and inhibits Stat3 activation using immunoprecipitaion in NPC cells. We found that exogenous expression of RKIP in $5-8$ F cells not only increased RKIP-interacting Stat3, but also decreased phospho-Stat3 level compared with control cells, indicating that RKIP inhibited Stat3 activation also by interacting with Stat3 in NPC cells (Figure 4D).

\section{RKIP downregulation enhances migration, invasion, and EMT-like molecular alterations by activating Stat 3 signaling in NPC cells}

Stat3 is constitutively activated in NPC cells [23], and activated Stat 3 promotes NPC cell invasion, metastasis and EMT [28-30], which encouraged us to determine whether RKIP downregulation promotes migration and invasion, and induces EMT in NPC cells via activating Stat3 signaling. We observed that transfection of Stat3 restored EMT-like molecular alterations, and cell migration and invasion reduced by RKIP overexpression in RKIP overexpression 5-8F cells (Figure 5A and 5B, Figure $2 \mathrm{~B}$ and $3 \mathrm{~B}$ ). Treatment of RKIP knockdown 6-10B cells with Stat3 inhibitor Stattic abolished EMT-like molecular alterations, and cell migration and invasion induced by RKIP knockdown (Figure 5A and 5B, Figure 2B and 3B). Collectively, these data demonstrated that Stat 3 mediated RKIP-regulating NPC cell migration, invasion and EMT, and RKIP downregulation promoted NPC cell invasion, metastasis and EMT by activating Stat 3 signaling.

Next, we determined whether the expression levels of RKIP and phospho-Stat3 were correlated in the cohort of NPC tissues and xenograft metastases using IHC. The results showed that phosph-Stat 3 level was significantly higher in NPCs with metastasis than that in tumors without metastasis, and in lymphonode metastases than that in paired primary NPCs (Figure 1A; Table 1). Correlation analyses revealed that there was an inverse association between RKIP and phospho-Stat3 expression in the NPC tissues $(P<0.01, \mathrm{r}=-0.585)$. Phospho-Stat3 expression was reduced in the xenograft metastases of RKIP overexpressing-5-8F cells compared with control 5-8F cells metastases (Figure 3D). Moreover, phospho-Stat3 expression level in the metastases of RKIP knockdown
6-10B cells was comparable to that of control 5-8F cells with high metastatic potential (Figure 3D). These results supported our in vitro findings, and suggested that RKIP downregulation might contribute to NPC cell metastasis in vivo by activating Stat 3 signaling.

\section{DISCUSSION}

In this study, we found that RKIP expression reduced in NPCs with metastasis as compared to NPCs without metastasis, and almost lost in lymphonode metastases. RKIP decrement in NPC correlated with high frequent metastasis, advanced clinical stage and poor patient survival, and was an independent predictor for reduced overall patient survival. To confirm the effects of RKIP downregulation on NPC cell invasion and metastasis, we established NPC cell lines with stable RKIP expression changes. We found that RKIP overexpression reduced while RKIP knockdown enhanced NPC cell invasion and metastasis both in vitro and in vivo. Moreover, RKIP knockdown 6-10B cells, parental cells of which lack metastatic potential, also produced pulmonary metastases in nude mice. Taken together, our results demonstrated that RKIP is a metastasis suppressor protein of NPC.

EMT is a key event in cancer invasion and metastasis [36]. Previous studies have indicated that RKIP inhibits EMT of prostate cancer cells [37, 38]. Therefore, we analyzed the effect of RKIP on the expression level of representative EMT markers in NPC cells. The results showed that RKIP knockdown increased Vimentin and $\mathrm{N}$-cadherin expression while decreased E-cadherin expression in NPC cells. RKIP overexpression decreased Vimentin and N-cadherin expression while increased E-cadherin expression in NPC cells. Moreover, downregulation of mesenchymal markers while upregulation of epithelial marker were also observed in the xenograft metastases of RKIP overexpressing-5-8F NPC cells. The expression levels of Vimentin, N-cadherin and E-cadherin in the xenograft metastases of RKIP knockdown 6-10B cells were comparable to those in the metastases of 5-8F cells with high metastatic potential. These results indicated that RKIP downregulation induced EMT-like cellular molecular alterations in NPC cells and xenograft metastases, and RKIP downregulation promoted NPC cell invasive and metastatic capability possibly by inducing EMT.

To determine the signaling mechanisms of RKIPregulating NPC cell invasion and metastasis, we firstly explored the effect of RKIP on the activity of ERK-1/2, NF- $\kappa$ B, GSK-3 $\beta$ and Stat3 signaling. The results showed that RKIP knockdown increased the phosphorylated levels of ERK-1/2, I $\kappa-\alpha$, IKK- $\alpha$ and Stat 3 , whereas decreased phosphorylated GSK-3 $\beta$ level in NPC cells. RKIP overexpression had the opposite effect on the phosphorylated levels of these proteins in NPC cells. The results indicated that RKIP inhibited ERK, NF- $\kappa B$, and 


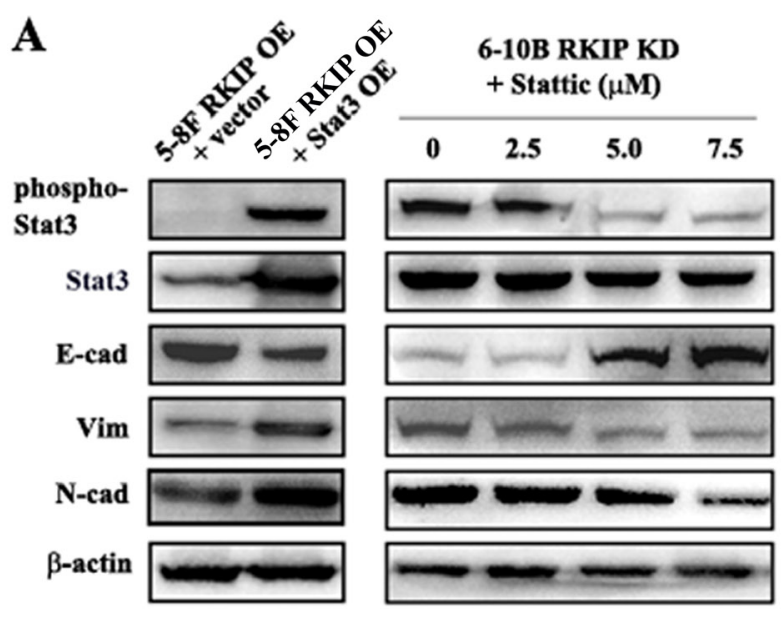

B
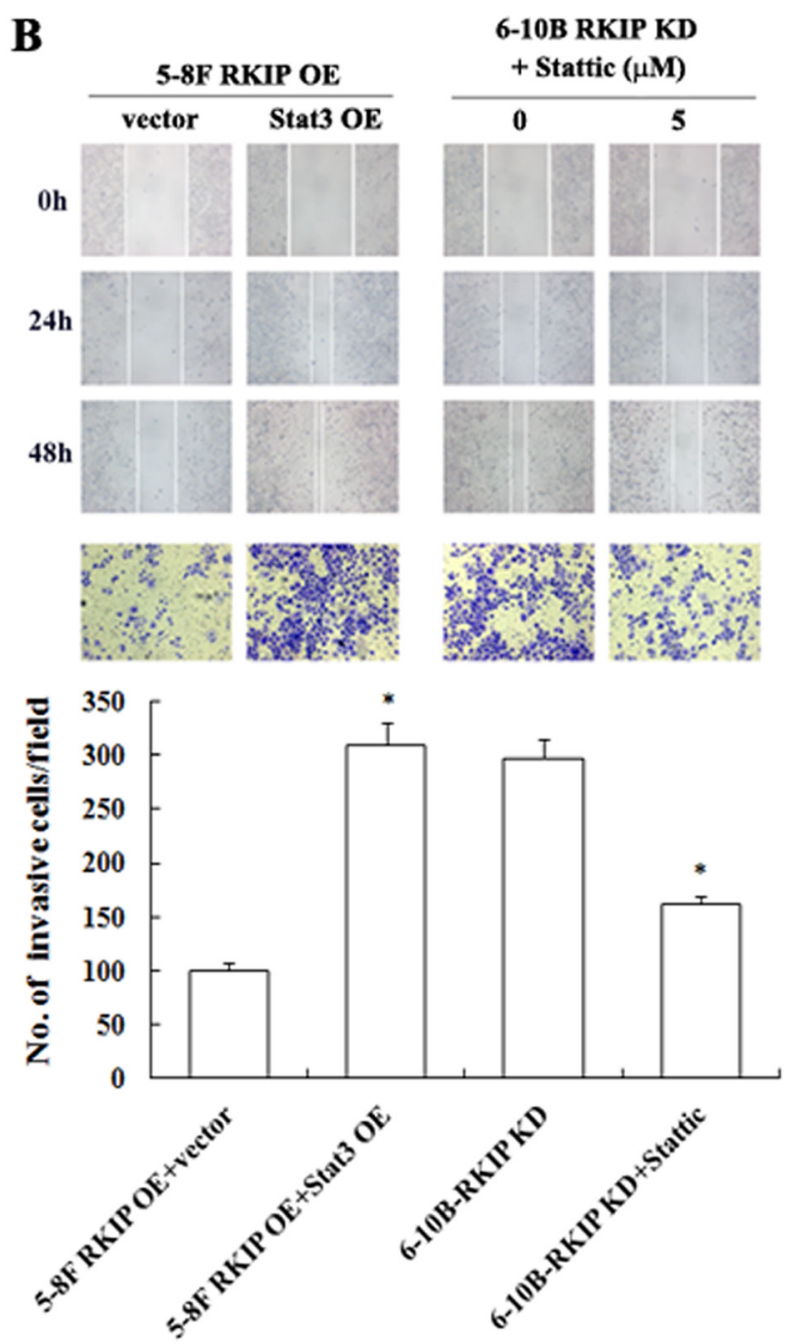

Figure 5: The regulation of RKIP on migration, invasion, and EMT marker expressions mediated by Stat3 signaling in NPC Cells. A. a representative result of Western blotting shows the levels of E-cadherin, N-cadherin and Vimentin in RKIP overexpression 5-8F cells transfected with pReceiver-M13-Stat3 or empty vector pReceiver-M13, and RKIP knockdown 6-10B cells treated with a range 0-7.5 $\mu \mathrm{M}$ Stat3 inhibitor Stattic. B. a representative result of scratch wound-healing assay (top) and Matrigel invasion assay (middle) of RKIP overexpression 5-8F cells transfected with pReceiver-M13-Stat3 or pReceiver-M13, and RKIP knockdown 6-10B cells treated with Stat3 inhibitor Stattic; (bottom) histogram of average numbers of invasive cancer cells per microscopic field in these cells. Columns, mean values; bars, S.D. *, $p<0.01$. Vector, transfcted with an empty vector; OE, overexpression; KD, knockdown. 
Stat3 signaling, and activated GSK-3 $\beta$ signaling in NPC cells, which is consistent with the previous reports in the other types of cancers $[5,6,8,9]$.

It is unknown whether Stat3 mediates RKIPregulating tumor cell invasion and metastasis. Therefore, we further investigated the effects of RKIP on Stat3 signaling in NPC cells. Immunofluorescent staining showed that RKIP knockdown increased while RKIP overexpression decreased the number of cells expressing nuclear phospho-Stat3 in NPC cells, indicating that RKIP could inhibit Stat3 nuclear translocation. Moreover, RKIP knockdown increased while RKIP overexpression decreased Stat3 luciferase reporter activity in NPC cells, demonstrating that RKIP could inhibit Stat3 transcriptional activity. Interestingly, we found although RKIP overexpression increased RKIP-binding Stat3, the phosphorylated level of RKIP-binding Stat3 was decreased in NPC cells, suggesting that RKIP inhibited Stat 3 activity by interacting with Stat 3 and then blocking its phosphorylation. Indeed, a recent study also showed that RKIP overexpression resulted in constitutive physical interaction with Stat 3 and blocked c-Src-phosphorylated and activated Stat3 [9].

Given that activated Stat3 promotes invasion and metastasis in a number of malignancies including NPC cells [24-26, 28-30], we determined whether Stat3 mediates RKIP-inhibiting NPC cell invasion and metastasis. We observed that Stattic treatment reduced while exogenous expression of Stat 3 enhanced in vitro tumor cell migration and invasion, as well as EMTlike molecular alterations in NPC cells. These results demonstrated that RKIP downregulation promoted NPC cell invasion, metastasis and EMT by activating Stat3 signaling. We also observed that phosph-Stat3 level was significantly higher in NPCs with metastasis than that in tumors without metastasis, and in lymph node metastases than that in paired primary NPCs. There was an inverse association between RKIP and p-Stat3 expression in NPC tissues. Moreover, phospho-Stat3 expression was reduced in the xenograft metastases of RKIP overexpressing-5-8F cells as compared to control metastases, and phospho-Stat3 expression level in the metastases of RKIP knockdown $6-10 \mathrm{~B}$ cells was comparable to that of $5-8 \mathrm{~F}$ cells with high metastatic potential. These results supported our in vitro findings, and suggested that RKIP downregulation might also contribute to in vivo NPC cell metastasis by activating Stat3 signaling.

In summary, our data demonstrate that: i) RKIP was downregulated in NPC cells and tissues with high metastatic potentials, and low RKIP expression was an independent predictor for poor overall survival of NPC patients; ii) RKIP downregulation promoted NPC cell invasion, metastasis and EMT-like molecular alterations both in vitro and in vivo; iii) RKIP inhibited Stat3 activation in NPC cells by interacting with and then blocking Stat3 phosphorylation in NPC cells; iv) RKIP downregulation promoted NPC invasion, metastasis and EMT-like molecular alterations by activating Stat3 signaling.

\section{MATERIALS AND METHODS}

\section{Patients and tissue specimens}

The one hundred and twenty-seven formalin-fixed and paraffin-embedded archival NPC tissue specimens (79 NPCs with metastasis and 48 NPCs without metastasis) between Jan 2007 and Dec 2009 were obtained from the First Hospital of Chengzhou City (Chengzhou, China) at the time of diagnosis before any therapy. In addition, 20 paired lymph node metastatic NPCs, and 30 normal nasopharyngeal mucosa were also collected. On the basis of the 1978 WHO classification [39], all tumors were histopathologically diagnosed as poorly differentiated squamous cell carcinomas (WHO type III). The clinical stage of all the patients was classified according to the 1992 NPC staging system of China [40]. All the patients underwent radio-chemotherapy treatment and were given follow-up. The follow-up period at the time of analysis was 6 to 78 months (average, $41 \pm 17.3$ ). The total survival was defined as the time from diagnosis to the date of cancer-related death or when censured at the latest date if patients were still alive.

\section{Reagents, plasmids and cell lines}

Anti-RKIP, Anti-phosph-Stat3 (Tyr705), anti-Stat3, anti-ERK-1/2 (Thr202/Tyr204), anti-ERK-1/2, antiphospho-GSK-3 $\beta$ (Ser9), anti-GSK-3 $\beta$, anti-phosphoIKK- $\alpha / \beta$ (Ser176)/ $\beta($ Ser177), anti-IKK- $\alpha$, anti-phospho-

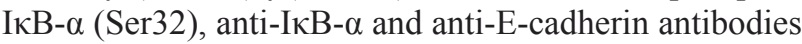
were purchased from Cell Signaling Technology. AntiVimentin and anti-N-cadherin antibodies were purchased from Abcom. Horseradish peroxidase-conjugated goat anti-rabbit $\mathrm{IgG}$ and anti-mouse $\mathrm{IgG}$ antibodies were purchased from Life technologies. Fluorescenceconjugated second antibodies (DyLight 594-labeled antirabbit Ig and anti-mouse Ig) were purchased from Vector Laboratories. Stat 3 kinase inhibitor Stattic was purchased from Merck. Recombinant plasmid pcDNA3.1(+)Flag-RKIP and lentiviral pGV248-puro-RKIP shRNA were established by Genechem (Shanghai, China), and confirmed by sequencing. The targets for human RKIP shRNA were 5'-GGTGGCGTCCTTCCGTAAA-3', the effect of which has been validated [41]. The shRNA targeting the 5'-TGGCTGCATGCTATGTTGA-3' sequence served as a negative control. Recombinant plasmid pReceiver-M13-Stat3 and control vector pReceiver-M13 were purchased from GeneCopoeia. Stat3 luciferase reporter vector pSTAT3-TA-luc and control 
vector pGL6-TA were purchased from Beyotime (Nanjin, China). pRL-TK vector was purchased from Promega. High metastatic NPC 5-8F and non-metastatic NPC 6-10B cell lines were maintained in RPMI-1640 medium supplemented with $10 \%$ FBS, $100 \mathrm{U} / \mathrm{ml}$ penicillin, and 0.1 $\mathrm{mg} / \mathrm{ml}$ streptomycin.

\section{Establishment of NPC cell lines with overexpression or knockdown of RKIP}

To generate NPC cell lines with RKIP overexpression, RKIP expression plasmid pcDNA3.1(+)Flag-RKIP and control plasmid pcDNA3.1(+) were transfected into non-metastatic 6-10B NPC cells using Lipofectamine 2000 (Invitrogen) according to the manufacturer's instruction, respectively. To generate NPC cell lines with RKIP knockdown, lentiviral pGV248puro-RKIP shRNA and pGV248-puro-control shRNA were used to transduce high metastatic 5-8F NPC cells according to the manufacturer's instruction, respectively. Cells were selected using neomycin or puromycin for 2 weeks, and NPC cell lines with stable overexpression or knockdown of RKIP and control cell lines were obtained.

\section{Scratch wound-healing assay}

Cell migration was determined by scratch woundhealing assay. Briefly, cells were grown in RPMI 1640 medium containing $10 \% \mathrm{FBS}$ overnight to confluence in a 6-well plate. Monolayers of cells were wounded by dragging a pipette tip. Cells were washed to remove cellular debris and allowed to migrate for 24-48h. Images were taken at 0,24 and $48 \mathrm{~h}$ after wounding under the inverted microscope.

\section{Matrigel invasion assay}

An invasion assay was performed in 24-well 8-mm pore size transwell chambers precoated with Matrigel (BD Biosciences) according to the manufacturer's instruction. The upper chamber was filled with $1 \times 10^{5}$ cells in RPMI 1640 medium containing $0.5 \%$ FBS. The lower chamber was filled with RPMI 1640 medium containing 10\% FBS as a chemoattractant. After incubation at $37^{\circ} \mathrm{C}$ for $48 \mathrm{~h}$, cells were fixed with $4 \%$ paraformaldehyde and stained with $0.5 \%$ crystal violet. Cells migrating through the Matrigel and the pores of the filter were counted from four random microscopic fields.

\section{Experimental lung metastasis in nude mice}

Nude male mice that were 4 weeks old were obtained from the Laboratory Animal Center of Central South University (Changsha, China) and were maintained under specific pathogen-free conditions. For experimental lung metastasis, mice ( $n=10$ each group) were injected intravenously with $1 \times 10^{6}$ cells/mouse via the tail vein. 6 weeks after injection, mice were sacrificed by cervical dislocation, and lungs were removed, weighed, and embedded in paraffin for hematoxylin and eosin (H.E.) and immunohistochemical staining. Lung metastases were examined macroscopically and detected in the paraffinembedded tissue sections stained with H.E. staining.

\section{Quantitative reverse transcription-PCR}

Total RNA was extracted from cells using Trizol reagent (Invitrogen). $2 \mu \mathrm{g}$ of total RNA was reversely transcribed for cDNA using the reverse transcription (RT) kit (Promega) and Oligo dT primer according to the manufacturer's instruction. The RT products were amplified by real-time PCR using QuantiFast SYBR green PCR kit (Qiagen) according to the manufacturer's instruction, and GAPDH was used as the internal control to normalize the expression levels of different genes. qRT-PCR was performed on the ABI Gene Amp PCR System 9700 (ABI). The primers used for amplification of indicated genes are listed in Supplementary Table S1.

\section{Western blotting}

Cells were lysed in RIPA buffer. An equal amount of protein in each sample was mixed with Laemmli buffer and subjected to sodium dodecyl sulfate-polyacrylamide gel electrophoresis (SDS-PAGE) separation, followed by blotting onto a polyvinylidene difluoride (PVDF) membrane (Millipore). Blots were blocked with 5\% nonfat dry milk or $3 \% \mathrm{BSA}$ for $2 \mathrm{~h}$ at room temperature and then incubated with primary antibody overnight at $4 \mathrm{C}^{\circ}$, followed by incubation with horseradish peroxidase-conjugated secondary antibody for $1 \mathrm{~h}$ at room temperature. The signal was visualized with an enhanced chemiluminescence detection reagent (Pierce). $\beta$-Actin was detected simultaneously using monoclonal mouse anti- $\beta$-actin antibody (Sigma) as a loading control.

\section{Immunohistochemistry}

Immunohistochemical staining of RKIP and phospho-Stat3 (Try705) in the cohort of clinical NPC tissues and xenograft metastases was performed on formalin-fixed and paraffin-embedded tissue sections. Briefly, tissue sections were treated with an antigen retrieval solution $[10 \mathrm{mmol} / \mathrm{L}$ sodium citrate buffer $(\mathrm{pH}$ 6.0)]; incubated with mouse monoclonal anti-RKIP antibody (1:800 dilution) (CST; \#13006), or rabbit polyclonal anti-phospho-Stat3(Tyr705) antibody (1: 400) (CST; \#9145) overnight at $4^{\circ} \mathrm{C}$; and then were 
incubated with 1:1000 dilution of biotinylated secondary antibody followed by avidin-biotin peroxidase complex (DAKO). Finally, tissue sections were incubated with 3', 3'-diaminobenzidine (Sigma) until a brown color developed and were counterstained with Harris' modified hematoxylin. In negative controls, primary antibodies were omitted.

The immunoreactions of RKIP and phospho-Stat3 were evaluated independently by two pathologists. Staining intensity was categorized: absent staining as 0 , weak as 1 , moderate as 2 , and strong as 3 . The percentage of stained cells was categorized as no staining $=0,<30 \%$ of stained cells $=1,30 \sim 60 \%=2$, and $>60 \%=3$. The staining score (ranging from 0-6) for each tissue was calculated by adding the area score and the intensity score. A combined staining score of $\leq 3$ was considered to be low expression, and $>3$ was considered to be high expression.

\section{Dual luciferase reporter assay}

$5 \times 10^{5}$ cells were plated into $60 \mathrm{~mm}$ culture dish chamber and incubated with RPMI-1640 medium containing $10 \%$ FBS for $12 \mathrm{~h}$. Cells were transiently cotransfected with $0.5 \mu \mathrm{g}$ of a reporter plasmid containing human STAT3 response element (pSTAT3-TA-luc) and 0.5 $\mu \mathrm{g}$ of pRL-TK plasmid using lipofectamine 2000 in serumfree medium. Cotransfection of pGL6-TA without STAT3 response element and pRL-TK plasmid into cells served as a control. Cells were harvested $48 \mathrm{~h}$ after transfection, and both firefly luciferase and renilla luciferase activities were measured with the Dual-luciferase reporter assay system (Promega) according to the manufacturer's instruction, and transcriptional activity of Stat3 was estimated using a luminometer.

\section{Immunofluorescent staining}

$2 \times 10^{4}$ cells were plated into chamber slides (Millipore) and cultured with RPMI-1640 medium containing $10 \% \mathrm{FBS}$ for $12 \mathrm{~h}$. Cells were fixed with $4 \%$ paraformaldehyde at room temperature for $15 \mathrm{~min}$, and then cell membranes were permeabilized with $0.1 \%$ Triton 100 at room temperature for $20 \mathrm{~min}$. Cells were washed with $1 \times$ PBS and blocked with $10 \%$ goat serum in PBS for $1 \mathrm{~h}$. Then cells were incubated with primary antibodies overnight at $4^{\circ} \mathrm{C}$. After washing with $1 \times$ PBS for three times, cells were incubated with secondary antibodies conjugated with Alexa Fluor 594 for 1h. The slides were washed three times with $1 \times \mathrm{PBS}$, counterstained with DAPI, mounted and stored at $4^{\circ} \mathrm{C}$ under dark conditions. Pictures were taken under a Leica DMI4000 microscope.

\section{Immunoprecipitation assay}

The cells were lysed in RIPA buffer. $1.0 \mathrm{mg}$ of proteins was incubated with $3 \mu \mathrm{g}$ of monoclonal mouseanti human RKIP antibody (Santa Cruz; sc-365973) for $4 \mathrm{~h}$ at $4^{\circ} \mathrm{C}$. Immunocomplexes were collected on protein A-agarose beads (Life Technologies), separated by $10 \%$ SDS-PAGE and electroblotted to PVDF membrane. Proteins were detected after incubation with specific antibodies described and identified using an enhanced chemiluminescence detection reagent(Pierce). Five percent of the sample was removed to verify and analyze proteins present for the immunoprecipitation input.

\section{Statistical analysis}

All experiments were carried out at least 3 times. Data were presented as the mean \pm standard deviation (SD). Statistical analysis was conducted using SPSS18.0 software. For comparisons between two groups, a Student t test or chi-square test was used, and for analysis with multiple comparisons, Oneway ANOVA test was used. Survival curves were obtained by using Kaplan-Meier method, and comparisons were made by using log-rank test. Univariate and multivariate survival analyses were conducted on all parameters by using Cox proportional hazards regression model. The Spearman rank correlation coefficient was used to determine correlation between RKIP and p-Stat3 expression levels in the NPC tissues. $P$ values less than 0.05 were considered to be statistically significant.

\section{Ethics statement}

This study was approved by the Institute Research Ethics Committee of Central South University, China. Written informed consent was obtained from all participants in the study. All animal experiments were undertaken in accordance with the Guide for the Care and Use of Laboratory Animals of Central South University, with the approval of the Scientific Investigation Board of Central South University.

\section{ACKNOWLEDGMENTS}

This work was supported by the National Basic Research Program of China (2013CB910502), the Major Program of National Natural Science Foundation of China (81230053), the National Key Technology R\&D Program of China (2013BAI01B07), and the National Natural Science Foundation of China $(81172559,81172302)$ 


\section{CONFLICTS OF INTEREST}

The authors disclose no potential conflicts of interest.

\section{REFERENCES}

1. Lo KW, To KF, Huang DP. Focus on nasopharyngeal carcinoma. Cancer Cell. 2004; 5:423-428.

2. Chan AT. Current treatment of nasopharyngeal carcinoma. Eur J Cancer. 2011; 47:S302-S303.

3. Lee AW, Poon YF, Foo W, Law SC, Cheung FK, Chan DK, Tung SY, Thaw M, Ho JH. Retrospective analysis of 5037 patients with nasopharyngeal carcinoma treated during 1976-1985: overall survival and patterns of failure. Int J Radiat Oncol Biol Phys. 1992; 23: 261-270.

4. Bernier I, Tresca JP, Jollés P. Ligand-binding studies with a $23 \mathrm{kDa}$ protein purified from bovine brain cytosol. Biochim Biophys Acta.1986; 871:19-23.

5. Yeung K, Seitz T, Li S, Janosch P, McFerran B, Kaiser C, Fee F, Katsanakis KD, Rose DW, Mischak H, Sedivy JM, Kolch W. Suppression of Raf-1 kinase activity and MAP kinase signalling by RKIP. Nature. 1999; 401:173-177.

6. Yeung KC, Rose DW, Dhillon AS, Yaros D, Gustafsson M, Chatterjee D, McFerran B, Wyche J, Kolch W, Sedivy JM. Raf kinase inhibitor protein interacts with NF-kappaBinducing kinase and TAK1 and inhibits NF-kappaB activation. Mol Cell Biol. 2001; 21:7207-7217.

7. Goel R, Baldassare JJ. Killing two birds with one RKIP. Trends Endocrinol Metab. 2004; 15:91-92.

8. Al-Mulla F, Bitar MS, Al-Maghrebi M, Behbehani AI, Al-Ali W, Rath O, Doyle B, Tan KY, Pitt A, Kolch W. Raf kinase inhibitor protein RKIP enhances signaling by glycogen synthase kinase-3 $\beta$. Cancer Res. 2011; 71:13341343.

9. Yousuf S, Duan M, Moen EL, Cross-Knorr S, Brilliant K, Bonavida B, LaValle T, Yeung KC, Al-Mulla F, Chin E, Chatterjee D. Raf kinase inhibitor protein (RKIP) blocks signal transducer and activator of transcription 3 (STAT3) activation in breast and prostate cancer. PLoS One. 2014; 9:e92478.

10. Escara-Wilke J, Yeung K, Keller ET. Raf kinase inhibitor protein (RKIP) in cancer. Cancer Metastasis Rev. 2012; 31:615-620.

11. Keller ET, Fu Z, Brennan M. The role of Raf kinase inhibitor protein (RKIP) in health and disease. Biochem Pharmacol. 2004; 68:1049-1053.

12. Fu Z, Smith PC, Zhang L, Rubin MA, Dunn RL, Yao Z, Keller ET. Effects of raf kinase inhibitor protein expression on suppression of prostate cancer metastasis. J Natl Cancer Inst. 2003; 95: 878-889.

13. Keller ET, Fu Z, Yeung K, Brennan M. Raf kinase inhibitor protein: a prostate cancer metastasis suppressor gene. Cancer Lett. 2004; 207: 131-137.
14. Fu Z, Kitagawa Y, Shen R, Shah R, Mehra R, Rhodes D, Keller PJ, Mizokami A, Dunn R, Chinnaiyan AM, Yao Z, Keller ET. Metastasis suppressor gene Raf kinase inhibitor protein (RKIP) is a novel prognostic marker in prostate cancer. Prostate 2006; 66:248-256.

15. Hagan S1, Al-Mulla F, Mallon E, Oien K, Ferrier R, Gusterson B, García JJ, Kolch W. Reduction of Raf-1 kinase inhibitor protein expression correlates with breast cancer metastasis. Clin Cancer Res. 2005; 11: 7392-7397.

16. Li HZ, Wang Y, Gao Y, Shao J, Zhao XL, Deng WM, Liu YX, Yang J, Yao Z. Effects of raf kinase inhibitor protein expression on metastasis and progression of human epithelial ovarian cancer. Mol Cancer Res. 2008; 6:917928.

17. Al-Mulla F, Hagan S, Behbehani AI, Bitar MS, George SS, Going JJ, García JJ, Scott L, Fyfe N, Murray GI, Kolch W. Raf kinase inhibitor protein expression in a survival analysis of colorectal cancer patients. J Clin Oncol. 2006; 24: 5672-5679.

18. Minoo P, Zlobec I, Baker K, Tornillo L, Terracciano L, Jass JR, Lugli A. Loss of raf-1 kinase inhibitor protein expression is associated with tumor progression and metastasis in colorectal cancer. Am J Clin Pathol. 2007; 127: 820-827.

19. Liu H, Li P, Li B, Sun P, Zhang J, Wang B, Jia B. RKIP suppresses gastric cancer cell proliferation and invasion and enhances apoptosis regulated by microRNA-224. Tumour Biol. 2014; 35:10095-10103.

20. Schuierer MM, Bataille F, Hagan S, Kolch W, Bosserhoff AK. Reduction in Raf kinase inhibitor protein expression is associated with increased Ras extracellular signal-regulated kinase signaling in melanoma cell lines. Cancer Res. 2004; 64: 5186-5192.

21. Woods Ignatoski KM, Grewal NK, Markwart SM, Vellaichamy A, Chinnaiyan AM, Yeung K, Ray ME, Keller ET. Loss of Raf kinase inhibitory protein induces radioresistance in prostate cancer. Int J Radiat Oncol Biol Phys. 2008; 72:153-160.

22. Li J, Wang Y, Song Y, Fu Z, Yu W. miR-27a regulates cisplatin resistance and metastasis by targeting RKIP in human lung adenocarcinoma cells. Mol Cancer. 2014;13:193

23. Wang Z, Luo F, Li L, Yang L, Hu D, Ma X, Lu Z, Sun L, Cao Y. STAT3 activation induced by Epstein-Barr virus latent membrane protein 1 causes vascular endothelial growth factor expression and cellular invasiveness via JAK3 and ERK signaling. Eur J Cancer. 2010; 46:29963006.

24. Devarajan E, Huang S. STAT3 as a central regulator of tumor metastases. Curr Mol Med. 2009; 9:626-933.

25. Huang S. Regulation of metastases by signal transducer and activator of transcription 3 signaling pathway: clinical implications. Clin Cancer Res. 2007; 13:1362-1366.

26. Wendt MK, Balanis N, Carlin CR, Schiemann WP. STAT3 
and epithelial-mesenchymal transitions in carcinomas. JAKSTAT. 2014; 3:e28975.

27. Germain D, Frank DA. Targeting the cytoplasmic and nuclear functions of signal transducers and activators of transcription 3 for cancer therapy. Clin Cancer Res. 2007, 13:5665-5669.

28. Liao Q, Zeng Z, Guo X, Li X, Wei F, Zhang W, Li X, Chen $\mathrm{P}$, Liang F, Xiang B, Ma J, Wu M, Tang H, et al. LPLUNC1 suppresses IL-6-induced nasopharyngeal carcinoma cell proliferation via inhibiting the Stat3 activation. Oncogene. 2014; 33:2098-2109.

29. Tsang CM, Cheung YC, Lui VW, Yip YL, Zhang G, Lin VW, Cheung KC, Feng Y, Tsao SW. Berberine suppresses tumorigenicity and growth of nasopharyngeal carcinoma cells by inhibiting STAT3 activation induced by tumor associated fibroblasts. BMC Cancer. 2013;13:619.

30. Lin $\mathrm{CH}$, Chao LK, Hung PH, Chen YJ. EGCG inhibits the growth and tumorigenicity of nasopharyngeal tumorinitiating cells through attenuation of STAT3 activation. Int J Clin Exp Pathol. 2014; 7:2372-2381.

31. Ho Y, Tsao SW, Zeng M, Lui VW. STAT3 as a therapeutic target for Epstein-Barr virus (EBV): associated nasopharyngeal carcinoma. Cancer Lett. 2013; 330:141149.

32. Chen Y, Ouyang GL, Yi H, Li MY, Zhang PF, Li C, Li JL, Liu YF, Chen ZC, Xiao ZQ. Identification of RKIP as an invasion suppressor protein in nasopharyngeal carcinoma by proteomic analysis. J Proteome Res 2008; 7:5254-5262.

33. Ruan L, Wang GL, Yi H, Chen Y, Tang CE, Zhang PF, Li MY, Li C, Peng F, Li JL, Chen ZC, Xiao ZQ. Raf kinase inhibitor protein correlates with sensitivity of nasopharyngeal carcinoma to radiotherapy. J Cell Biochem. 2010; 110:975-981.

34. Li SW, Wang H, Xiang YQ, Zhang HB, Lv X, Xia WX, Zeng MS, Mai HQ, Hong MH, Guo X. Prospective study of prognostic value of Raf kinase inhibitory protein and pretreatment plasma Epstein-Barr virus DNA for distant metastasis in locoregionally advanced nasopharyngeal carcinoma. Head Neck. 2013; 35:579-591.

35. Chatterjee D, Sabo E, Tavares R, Resnick MB. Inverse association between Raf Kinase Inhibitory Protein and signal transducers and activators of transcription 3 expression in gastric adenocarcinoma patients: implications for clinical outcome. Clin Cancer Res. 2008; 14:2994-3001.

36. Thiery JP, Acloque H, Huang RY, Nieto MA. Epithelialmesenchymal transitions in development and disease. Cell. 2009; 139: 871-890.

37. Beach S, Tang H, Park S, Dhillon AS, Keller ET, Kolch W, Yeung KC. Snail is a repressor of RKIP transcription in metastatic prostate cancer cells. Oncogene. 2008; 27:22432248 .

38. Baritaki S, Huerta-Yepez S, Sahakyan A, Karagiannides I, Bakirtzi K, Jazirehi A, Bonavida B. Mechanisms of nitric oxide-mediated inhibition of EMT in cancer: inhibition of the metastasis-inducer Snail and induction of the metastasissuppressor RKIP. Cell Cycle. 2010; 9:4931-4940.

39. Shanmugaratnam K, Sobin LH. The World Health Organization histological classification of tumours of the upper respiratory tract and ear. A commentary on the second edition. Cancer. 1993; 71:2689-2697.

40. Qian CN, Guo X, Cao B, Kort EJ, Lee CC, Chen J, Wang LM, Mai WY, Min HQ, Hong MH, Vande Woude GF, Resau JH, Teh BT. Met protein expression level correlates with survival in patients with late-stage nasopharyngeal carcinoma. Cancer Res. 2002; 62:589-596.

41. Trakul N, Menard RE, Schade GR, Qian Z, Rosner MR. Raf kinase inhibitory protein regulates Raf-1 but not B-Raf kinase activation. J Biol Chem. 2005; 280:24931-24940. 